\title{
System Modeling and Simulation of a Wind Power Generation with Doubly Fed Induction Generator
}

\author{
Yun SHI ${ }^{1, a}$, Ai LIU ${ }^{2, b}$,Chengwu LIN, \\ ${ }^{123}$ Department of Electrical Engineering, Qingdao Binhai University, Qingdao, 266555, China \\ aemail: 48137474@qq.com, b8831148@qq.com, c linchengwu@sina.com
}

\begin{abstract}
Keywords: Design Variable Speed Constant Frequency (VSCF); Doubly Fed Induction Generator (DFIG); System Control Model; Simulation; Excitation Control System
\end{abstract}

\begin{abstract}
Variable speed constant frequency (VSCF) doubly fed wind power generation system, which is mainly composed of doubly fed induction generator (DFIG), excitation control system and wind turbine, is a complicated system of electromechanical energy transformation and control. It is quite necessary to study system modeling and simulation of the VSCF doubly fed wind power generation system. Unified control model of VSCF doubly fed wind power generation system is established in this paper based on stator flux orientation vector control, which not only directly reflects structure parameters of DFIG and wind turbine, excitation parameters, and the relationship between variable pitch control and output power, but also indicates in theory that the running characteristics of DFIG and the technical superiority for being used in VSCF wind power generation system. System control model of output power control strategy of VSCF doubly fed wind power generation system which running at different wind speed is established with computer simulation. Simulation results indicate that the established unified control model is brief, instinctive and feasible, which conduces to the theoretical study on application systems of DFIG and to the design on excitation control system.
\end{abstract}

\section{Introduction}

Variable speed constant frequency (VSCF) doubly fed wind power generation system with its remarkable technical advantages is widely used in large capacity parallel operation of wind turbines $^{[1]}$. In 2009, new wind power generation system in the world, the variable speed constant frequency doubly fed unit accounted for more than $80 \%$. 10MW variable speed constant frequency doubly fed wind power generator is developing in Europe now ${ }^{[2]}$.VSCF doubly fed wind power generation system, which is mainly composed of three components: doubly fed induction generator (DFIG), excitation control system and wind turbine, is a complicated system of electromechanical transformation and control. Thereby it is quite necessary to study system modeling and simulation of VSCF doubly fed wind power generation system in terms of system. Currently, the study on the modeling and simulation mainly concentrates on two respects: the one is oriented towards the DFIG; the other is oriented towards the rotor excitation control system ${ }^{[3]}$. It is difficult to build a unified model including wind turbines structure parameters and control model, which can effectively reflect running characteristic and control property of DFIG, so it is not convenient to analyze and study the whole characteristic of wind power generation system.

Based on theoretical analysis and experimental research and relative research results, the mathematic model, which could characterize the whole structure parameters and control parameters of VSCF doubly fed wind power generation system, is established in this paper. For running below and above rated wind speed, the control strategy has been studied by theoretical analysis and simulation, which conduce to the theoretical study on application systems of DFIG and to the design on excitation control system.

\section{Modeling of Doubly Fed Induction Generator and Excitation Control System}

The excitation control system consists of the converter and the microcontroller. The latter 
controls the former. The output voltage of the converter is the rotor excitation voltage of the DFIG. So, the mathematic model of the converter is equal to the model of the excitation control system, whose simplified structure schematic diagram can be seen in Fig. 1.

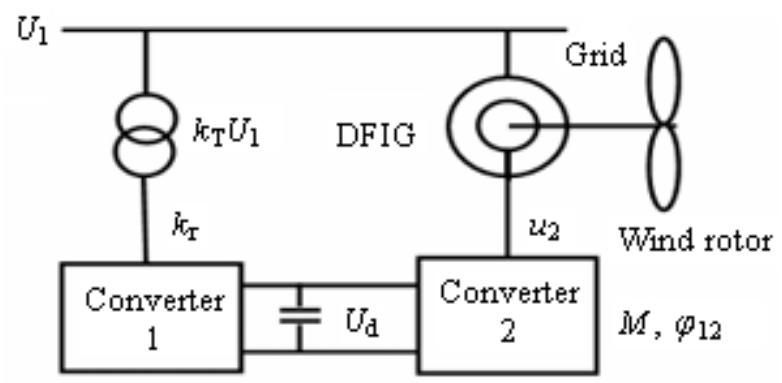

Fig.1 Overview of the simplified structure schematic diagram of the doubly fed induction generator

As the DFIG which needs incorporate in the power grid, its stator voltage and frequency are constant; if the resistance of stator winding is neglected, the stator voltage vector $U_{1}$ will lag behind the stator flux $90^{\circ}$. In the synchronous rotating reference frame ( $d q 0$ reference frame), assuming both the reference axis $d$ and stator flux have the same direction, and then the reference axis $q$ and stator voltage vector have the same direction, and both the axis $d$ component of stator voltage and the axis $q$ component of stator flux are zero. Therefore, the control model and the control strategy are simplified ${ }^{[4][5]}$. In the steady state, the active power and reactive power of output power of DFIG can be expressed as follows:

$$
P=\frac{(1-s) \operatorname{tg} \delta}{4 X_{1}\left(r_{2}^{2}+s^{2} A^{2}\right)}\left[9 U_{1}^{2} X_{m} k_{r} k_{T} M r_{2} \sin \varphi_{12}-9 U_{1}^{2} X_{m} k_{r} k_{T} M s A \cos \varphi_{12}+6 U_{1} X_{m} s^{2} A B\right]
$$

Where, $A=\frac{X_{m}^{2}}{X_{1}}-X_{2} ; B=\frac{X_{m}}{X_{1}} U_{1}$

The equation (1) is the control model of the DFIG, which is composed of hardware structure parameters and control parameters of excitation control system. Because both the transformation ratio $k_{T}$ of transformer and the variable current coefficient $k_{r}$ of converter 1 are approximate to constant, if the stator voltage, the power grid frequency and wind speed keep constant, the mathematic model of DFIG is established by stator flux orientation vector control technology, and then its output active power and reactive power are only determined by the modulation factor $M$ of the converter 2 and the phase angle $\varphi_{12}$ between the inverter output voltage and the generator voltage.

\section{Power Control Performance of Wind Power Generation System}

As the capacity of grid-connected wind power generation system is steadily increasing, the weight of the blades of large-scale wind power generation system has been up to several tons. It is rather problematic to manipulate such huge inertial body and to keep the response speed up with the variations of wind speed. The VSCF doubly fed wind power generation system has the ability to overcome this disadvantage and to improve the wind energy efficiency. Different control strategies can be adopted at different wind speed.

\section{Power Performance Model Below Rated Wind Speed}

Under the condition of given wind speed, the power of wind turbine capturing is determined by the wind power utilization coefficient $C_{P}$. If wind turbine always runs at the point of $C_{P \max }$ under any wind speed, the optimum wind power capture can be realized and its output power is improved. According to [6], just keep the tip speed of a blade of wind turbine $\lambda=\lambda_{\text {opt }}$, it can keep up running in the case of $C_{P \max }$. Only in the consideration of output active power of wind power generation system, output power control model of VSCF doubly fed wind power generation system running below rated wind speed is obtained as follows: 


$$
P_{o p t}=\frac{1}{\sqrt{k C_{P \max }}}\left[\frac{9 U_{1}^{2} X_{m} k_{r} k_{T} M\left(r_{2} \sin \varphi_{12}-s A \cos \varphi_{12}\right)}{4 X_{1}\left(r_{2}^{2}+s^{2} A^{2}\right)} \tan \delta+\frac{6 U_{1} X_{m} s^{2} A B}{4 X_{1}\left(r_{2}^{2}+s^{2} A^{2}\right)} \tan \delta\right]^{\frac{3}{2}}
$$

Where, $k=\frac{1}{2} \rho A_{s}\left(\frac{v_{T S}}{9}\right)^{3} ; v_{T S}$ is the tip liner velocity of a blade at synchronous speed.

The equation above is the output power control model of the VSCF doubly fed wind power generation system running below rated wind speed. The model combines DFIG, rotor excitation system and wind power turbine together. It intuitively reflects the relationship between doubly fed wind power generation output power, rotor excitation control parameters, the structure parameters of DFIG and wind turbines.

\section{Power Performance Model Above Rated Wind Speed}

As for running above rated rotating speed, both rotor excitation system and variable pitch system work simultaneously in the process of constant power control of the VSCF doubly fed wind power generation system. The nature of variable pitch control is to adjust wind energy utilization coefficient $C_{P}(\beta, \lambda)$.If all loss is neglected, output power of DFIG stator winding is limited at rated power, and its expression is showed as follows:

$$
P_{1}=\frac{25 \rho A_{s} C_{P}(\beta, \lambda)}{\left(50-f_{2}\right)} v^{3}
$$

Where, $f_{2}$ is negative value when running above synchronous speed.

The equation above is the constant power control model of VSCF doubly fed wind power generation system running above rated wind speed. When wind speed varying slowly, pitch control system keeps output power basically stable by adjusting pitch angle $\beta$. However, When wind speed varying quickly, adjusting speed of the pitch control system with huge inertia cannot keep up with variation of wind speed, but by adjusting rotor excitation current frequency $f_{2}$ and changing power angle $\delta$ of DFIG, and then quick fast varying various wind power is converted to the dynamic power of wind turbines, thereby the DFIG output power is kept fundamentally stable.

\section{Simulation Research of DFIG Control System}

According to the analysis above, the VSCF doubly fed wind power generation system has different excitation control strategies when running below and above rated wind speed. Its simulation waveforms are showed in Fig.2.

Assuming random variable curve of wind speed is showed in Fig. 2(a). If the rated wind speed is $12 \mathrm{~m} / \mathrm{s}$, according to equation (1), under the principal of optimum wind energy capture to control output power of DFIG when running below rated wind speed. Relative curves of DFIG output power, wind energy utilization coefficient, rotor excitation voltage, rotor excitation frequency with respect to wind speed are showed in Fig.2 (b), (c), (d), (e), (f). Output power curve is directly proportional with cube of wind speed, and both curves are basically similar. The waveform of rotor excitation voltage in synchronous rotating reference frame $d q 0$ is showed in Fig.2 (e). In three-phase quiescent reference frame $(a b c)$, rotor excitation voltage waveform is sinusoidal wave with its amplitude and frequency varying, as presented in Fig.2 (f). The outside enveloping curve of excitation voltage sinusoidal waveform is consistent with rotor excitation voltage waveform in synchronous rotating reference frame $d q 0$. 


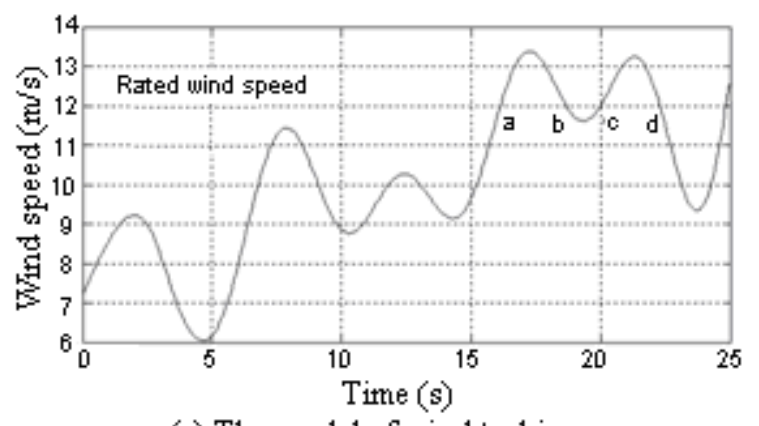

(a) The model of wind turbine

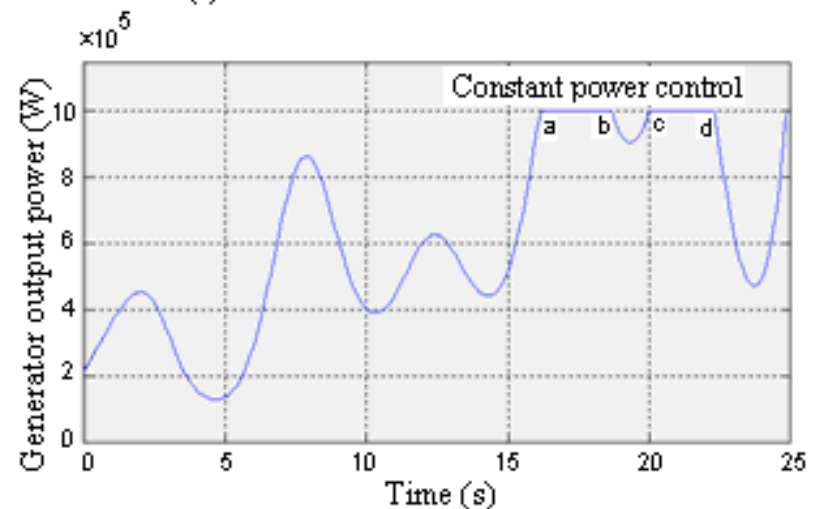

(c) The curve of output power of variable speed variable pitch DFIG wind power generation system

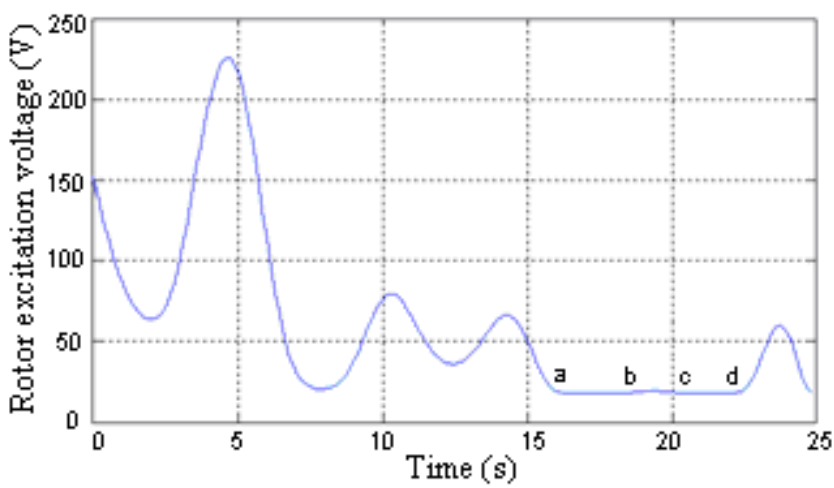

(e) Rotor excitation voltage waveform with respect to different wind speed

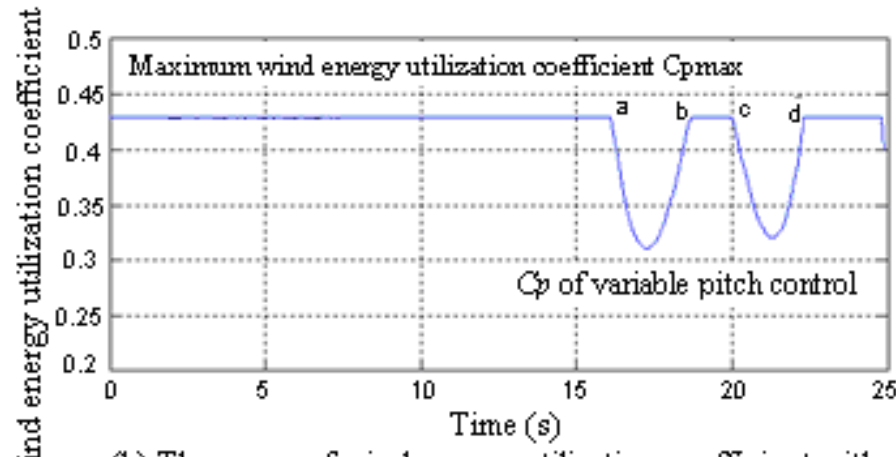

(b) The curve of wind energy utilization coefficient with respect to variation of pitch

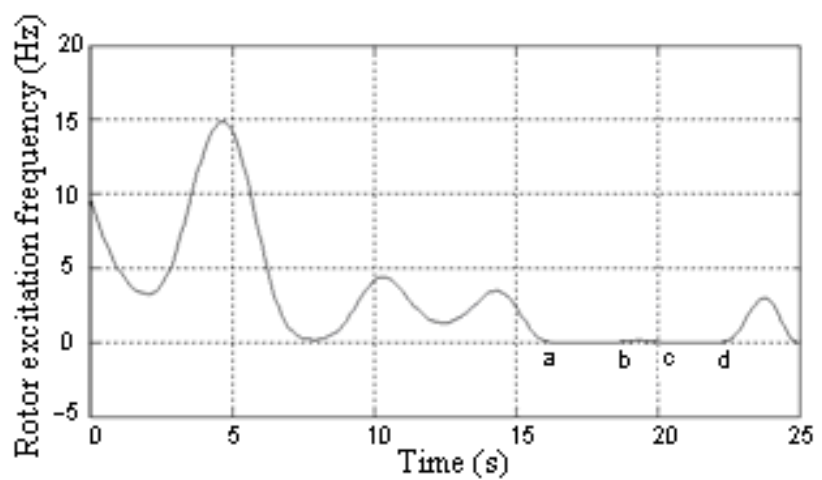

(d) Rotor excitation frequency with respect to different wind speed (rotating speed)

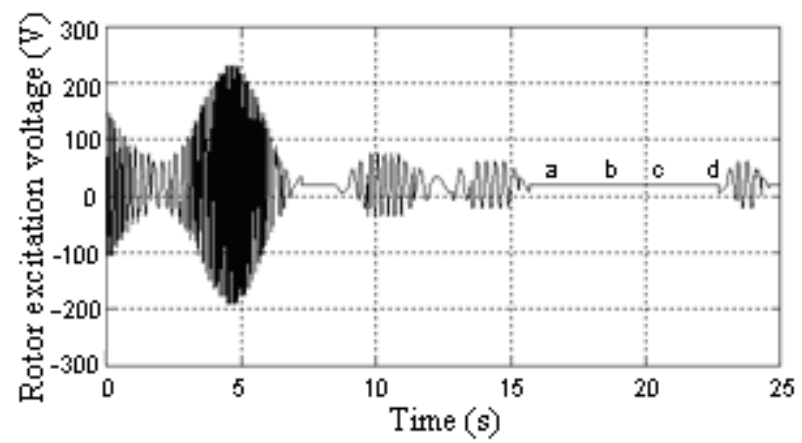

(f) Rotor excitation voltage waveform in three-phase quiescent reference

Fig. 2 Running characteristic waveforms of variable speed variable pitch DFIG wind power generation system

\section{Conclusion}

Theoretical analysis and simulation results suggest:

- Under the condition of stator voltage, the power grid frequency and wind speed kept constant, output power of DFIG is determined by modulation factor $M$ of rotor excitation system converter, phase angle $\varphi_{12}$ between stator voltage and rotor voltage, and wind energy utilization coefficient $C_{P}(\beta, \lambda)$.

- For running below rated wind speed, just adjusting $M$ and $\varphi_{12}$ to control wind turbine rotating speed and keep wind turbine running at $C_{p \max }$, thereby optimum wind energy capture of wind turbines is realized and system running efficiency is enhanced.

- For running above rated wind speed, constant power control strategy is used for VSCF doubly fed wind power generation system, according to variation of wind speed, both rotor excitation system and variable pitch system work simultaneously, thereby system dynamic response speed 
is improved.

- Simulation results show that the established unified control model is brief, instinctive and feasible, which conduces to the theoretical study on application systems of DFIG and to the design on excitation control system.

\section{References}

[1] Hongmei Fan. The Research and Thinking of World Wind Power Industry Status Quo [J]. Defence Industry Conversion in China. 2016(1):62-66

[2] Bo Liu, Zhijia He, Hao Jin. Wind Power Status and Development Trends [J]. Journal of Northeast Dianli University. 2016,36(2):7-13

[3] Xinran Li, Yahui Ma, Yijia Cao, Zhenhua Xu, Weijian Liu, Longhui Hu. An Equivalent Model of Doubly-Fed Wind Generation System [J].Transactions of China Electrotechnical Society. 2015,30(8):210-217

[4] BIANCHI F D, DE BATTISTE H, MANHZ R J. Wind Turbine control systems [M].London: Springer. 2007.

[5] Chenwu Lin, Xiaodong Wang, Xingjia Yao.Theoretical Analysis and Experiment on Power Performance of Doubly-Fed Wind Power Generator [J]. ACTA Energiae Solaris Sinica. 2008,29(3):328-331.

[6] Ye Hangye, A Control Technology of Wind Turbine Generator System [M]. Machine Building Press Beijing, P.R. China 2002. (in Chinese).

[7] Ion Boldea, Lucian Tutelea, Ioan Serban, Variable Speed Electric Generators and Their Control[J]. An Energing Technology. Journal of Electrical Engineering, 2002(3):20-28.

[8] Gu Chenglin, Wei Zhengchao, Huang Shenghua, Tao Xingshi, VSCF Generator with Vector Control for Rotor A.C. Exciting Current [J]. Proceedings of the CSEE, 1996,16(2):199-124.

[9] S. Muller, M. Deicke, R. W. D. Doncker, Doubly fed induction generator system for wind turbines[J]. IEEE Induction Applications Magazine.2002,8(3):26-33. 